\title{
A CASE OF BILATERAL GLIOMA OF THE RETINA*
}

\author{
HOWARD F. HANSELL, M.D. \\ PHILADELPHIA
}

The facts concerning the origin, course and prognosis of the nonpigmented cancer of the retina occurring in children are well known. Wintersteiner's classical monograph, in which he describes 467 cases, has been referred to as a basis of their remarks by authors who have published accounts of individual cases. Wehrli ${ }^{1}$ believes that retinal hemorrhages are the prime etiologic factor, because he has found rosettes, the centers of which were formed by the smallest vessels. These vessels were fully developed and for the most part degenerated, while their lumen contained remnants of red blood corpuscles surrounded by epithelial-like tumor cells. ${ }^{2}$ Lindenfeld $^{3}$ in the study of the normal eyes of the fetus speaks of "granular rosette folds and folds of undifferential cells. From the cells may be derived the similarly arranged cells of retinal glioma." Fuchs' ${ }^{{ }^{4}}$ description of the pathology and changes voices the generally accepted opinion:

It develops ordinarily from two granular layers of the retina. The tumor is composed of small, cylindrical, epithelial cells and a soft basement substance. In many cases the cells are arranged about an open space, like the cross section of a gland tubule. The multiplication of the tumor cells takes place mainly in the immediate vicinity of the numerous wide blood vessels. Here are the youngest cells which displace the older cells, the latter undergoing necrosis. Neoplasm germs pass from the degenerated retina into the choroid and vitreous, where they subsequently develop into small independent nodules.

In considering the etiology, heredity should be given an important place. Many are the instances recorded in which the disease has manifested itself in the parents and children, or in several children of the same parents. Fuchs ${ }^{4}$ says, "A congenital morbid disposition very often lies at the bottom of glioma" and illustrates his statement by the following history: a 4 year old boy with advanced and perforating glioma of the right eye; a 2 year old brother with glioma of the right eye; finally a child of the same parents a few months old, with typical congenital coloboma of the iris and choroid. De Gouva ${ }^{5}$

* Read before the Section on Ophthalmology, College of Physicians, Philadelphia, March 18, 1915.

1. Wehrli: Graefe's Arch. f. Ophthal., 1909, p. 504.

2. Ophth. Year Book, 1910.

3. Lindenfeld: Klin. Monatsb. f. Augenh., April, 1913.

4. Fuchs: Text Book, edited by Duane.

5. De Gouva: On the Heredity of Glioma of the Retina, Ann. d. Oculist, January, 1910, cxliii. 
removed the right eye of a 2 year old boy for glioma in 1872. There was no recurrence, and on growing up he married a woman in whose family there was no tendency to the formation of neoplasm. They had seven children, the second and third of whom, both girls, died of double retinal glioma. Von Hoffman, Jr., ${ }^{6}$ and Owens ${ }^{7}$ recorded other instances.

The list of affections which may be confounded with glioma and, which are usually classified under the unexpressive and negative term of "pseudoglioma," is appallingly large, and the diagnostician who endeavors to be accurate and specific cannot be satisfied with the two classes of glioma and pseudoglioma. Curtil ${ }^{\mathrm{s}}$ enumerates the affections to be differentiated: metastatic ophthalmia, especially in the form of exudative choroiditis; metastatic or traumatic exudative or suppurative lesions of the vitreous; choroidal tuberculosis; simple detachment of the retina; certain congenital anomalies ; cysticercus of the deep membranes of the eye.

It is not enough to say prior to dismissing the subject of differentiation that the history and clinical symptoms of true glioma would indicate the diagnosis. While this may be true in some of the diseases mentioned, it is not true for all. Simple retinal detachment, for example, rarely occurs spontaneously. Malignant myopia, traumatism or constitutional affections, usually point to the etiology. Moreover, the separated retina is wavy, its arteries and veins of the same dark color and readily seen, and when transillumination may be employed, throws no dark shadow. Metastatic choroiditis has a distinct history, occurs at any age, is rapidly progressive, and has a dark yellow or reddish color and not the almost pink white of glioma. Advanced choroidal tuberculosis is almost never found in very young children and may be regarded as a local sign of general tuberculosis.

Congenital anomalies remain unchanged in their appearance for many years. Cysticercus may be diagnosed in most instances with the ophthalmoscope. Friedenwald ${ }^{9}$ and de Schweinitz ${ }^{10}$ cite cases of "retinitis with massive exudation" that resemble glioma in their ophthalmoscopic appearance. They are essentially different in their etiology, history and course and will not be confused by the thoughtful observer. In a case recorded by $\mathrm{Krauss}^{11}$ and in others to which he refers in his paper, the diagnosis is more difficult. A boy of 8 received an injury to the eye at birth. Seven months before examination, and

6. Von Hoffman, Jr.: Heidelberg Congress, 1908.

7. Owens: Royal London Ophth. Hosp. Rep., 1905.

8. Curtil: Rev. gén. d'ophtal., Dec. 31, 1910.

9. Friedenwald: Trans. Am. Ophth. Soc., 1914, xii, Part iii.

10. de Schweinitz: Trans. Am. Ophth. Soc., 1914, xii, Part i.

11. Krauss: Ophthalmology, April, 1913. 
several times since, there had been signs of moderate inflammation. The pupil was dilated and fixed, anterior chamber shallow and a few posterior synechiae were present. A greenish-yellow reflex shone from behind the lens on the temporal side, and later, all around the pupil. The eye was enucleated. There was total retinal detachment, subretinal hemorrhages and a mass of partly organized inflammatory exudate between the retina and the lens. The blood vessels of the retina were degenerated but the iris, choroid and sclera were practically normal. I believe his case belongs to a special group properly called "pseudoglioma" which originates primarily in the retina. I agree with those who hold that there is a distinct disease of the retina occurring in children which produces clinical symptoms closely simulating glioma and is of retinal and not choroidal origin. Even in Krauss' case real glioma might be excluded before enucleation on account of the age of the patient, the recurring attacks of inflammation and the absence of the signs of secondary glaucoma.

Devereux Marshall states that the statistics of the Moorfields Hospital show that about 60 per cent. of the cases of glioma occur in the first two years of life and that about 80 per cent. occur during the first three years. He studied thirty-two cases; of these there were fifteen which had exceeded the three year limit, the time running from three years and four months to six years and nine months. Wintersteiner found 75 per cent. within the first three years. Curt Adam ${ }^{12}$ studied the records of forty-seven cases. All the patients were less than 12 years old, 94 per cent. being under 4 years. The attacks of inflammation, the posterior synechiae and the yellowish-green foreign material in the posterior chamber, and the absence of secondary glaucoma, point to retinal or choroidal inflammation rather than a glioma.

\section{CASE REPORT}

History.-Boy 2 years old. Parents healthy. No family history of cancer or other forms of tumor or of congenital affections of the eyes. The patient has a sister two years older than himself who is apparently well and strong. One year ago a "shine" was noticed in the pupil of the left eye. At present the eyeball is larger than its fellow, the pupil dilated and immobile, anterior chamber shallow, lens clear and the entire vitreous occupied by a shining, white, irregular mass, traversed by a few blood vessels. Tension +1 . No perception of light. Under chloroform anesthesia, and through the pupil dilated with homatropin, a small, round, white mass projecting several diopters into the vitreous and situated close to the nerve head on its temporal side was seen in the right eye. An object held in the center of the field of fixation was not seen by the child, but even small objects were readily perceived in the periphery. The left eye was enucleated. The pathologist's report is as follows:

Pathologist's Report.-The specimen is that of an eyeball with attached portion of optic nerve. It measures 2.8 by $2.1 \mathrm{~cm}$. and weighs $3.8 \mathrm{gm}$. The eyeball is soft and the anterior chamber is partly collapsed. There is no apparent

12. Adam, Curt: Ztschr. f. Augenh., 1911, xxv, 330. 
external evidence of disease, except for a marked grayish opacity of the lens. On section, after hardening the eyeball, an irregularly outlined, grayish, soft tumor mass occupies the vitreous, apparently arising near the entrance of the optic nerve and extending into the vitreous to within a few millimeters of the lens. This mass measures 1.4 by $0.9 \mathrm{~cm}$. in its greatest diameters. The retina everywhere appears to be intact.

Histology: The sections show the tumor mass apparently arising from the granular layers of the retina, and made up of numerous small round cells with deeply staining nuclei lying amongst a fairly abundant network of neuroglia fibers. The blood vessels, with well formed walls and filled with red cells, appear directly amongst the cellular elements. The tumor growth has not involved the optic nerve.

Diagnosis: Glioma of retina.

Subsequent Course.-Three weeks later the left orbit was fitted with an artificial eye. The tumor in the right eye had increased in size and vision was measurably reduced. It was my distasteful duty to inform the parents that enucleation of the right eye must be performed as soon as vision should be lost, because by this means only was there a chance of saving the child's life.

My situation was exactly that described by Jacqueau ${ }^{13}$ and doubtless experienced by all who have had cases of bilateral glioma to deal with. He emphasized the tragic dilemma of the surgeon who is called on to render a decision in such cases. Van Duyse ${ }^{14}$ in discussing Gallemaert's case of double glioma says that even in such instances the patient may survive if enucleation has not been delayed too long. He referred to a case of his own in which fourteen months had elapsed without recurrence since enucleation of the second eye, which had been removed two years after the first.

Postponement of enucleation is fatal. Once the diagnosis is established, sentimental objection by parents, and alas! sometimes by the family physician, should be given no serious consideration. The disease will surely spread, either by rupture of the sclera and extension to the orbital contents, or posteriorly along the nerve, and then enucleation or even evisceration would be useless. Spontaneous cure cannot be expected, notwithstanding Lindenfeld's ${ }^{15}$ experience, who reports a case of spontaneous cure, the third of its kind to be supported by pathologic findings. He saw a 4 year old child with fungoid glioma of the right eye and a shrunken left globe. Both eyes were enucleated. The clinical diagnosis of bilateral glioma was confirmed histologically only as regards one eye, since no trace of glioma could be demonstrated in the shrunken eye. But the belief that this eye had previously suffered from the same condition was established by the entire clinical history and course of the disease. The "spontaneous cure" was due to complete necrosis of the tumor. This "pathologic cure" is to my mind even worse than enucleation.

13. Jacqueau: Clin. Ophth., 1912, xix, 733.

14. Van Duyse: Soc. Belge d'ophth., 1911, xxv, 19.

15. Lindenfeld: Graefe's Arch. f. Ophthal., 1912, Ixxxvi, 141. 
In the bilateral cases, which constitute about 25 per cent. of the total number, the disease begins in one eye and the second eye is involved some months later. The question arises whether prompt enucleation would save the second eye. In other words, could the second eye become involved by sympathy?

In this connection the four cases reported by Ayers ${ }^{16}$ are of interest: 1. Enucleation was performed when the tumor had advanced to the cornea and quite filled the globe. The patient is now 14 years of age and in good health. 2. The eye was enucleated after blindness of several months. "This child is now $\&$ years old and in excellent health." 3 . The tumor was almost in contact with the lens, the pupil dilated, and $T+1$. The child died two weeks after enucleation from extension of the growth into the brain. 4. Enucleation. "The child is now $2 \frac{1}{2}$ years old and bids fair to pass the three years' limit of immunity."

These histories emphatically negative the supposition that the sound eye is involved sympathetically.

Glioma may be briefly described as a malignant tumor arising from the granular layers of the retina, almost pure white, traversed by a few blood vessels, steadily advancing, without pain or symptom of constitutional irritation, until it has reached its second or glaucomatous stage. Unless the eyeball is enucleated, the tumor will perforate the coats of the eye and invade the orbit, or it will travel backward in the optic nerve and invade the brain. The only conservative treatment is the enucleation of the eye at the earliest moment. By this means the second eye may not be involved and the life saved. De Kleijn ${ }^{1 i}$ states concerning four cases in which the optic nerve was microscopically free from disease at the time of operation, that the subsequent records show no fatalities. When the optic nerve was affected but not up to the point of division, two patients had been well for eight and seven years, respectively, and four had died. Of five cases in which the optic nerve was affected at the point of section, only one patient had lived, the interval since operation being four years. The threeyear limit is generally accepted. Statistics show that fatalities occur as a rule within the first year, and should the patient survive without recurrence until the termination of the third year, the prognosis is favorable.

1528 Walnut Street.

16. Ayers: Arch. Ophthal., July, 1906.

17. De Kleijn: Arch. f. Ophthal. (Graefe's), 1911, 1xxx. 371. 